\title{
Medications for Ménière's disease?
}

The medical treatment of patients with Ménière's disease has long been controversial. The placebo effect of drugs used in this condition, along with the fluctuating nature of symptoms, has made proper assessment of efficacy difficult. Two drugs that have been used are betahistine and loop diuretics. The recently published 'BEMED' trial is a multicentre, double-blind, randomised, placebo-controlled, phase III trial on the use of betahistine dihydrochloride in Ménière's disease, conducted in 14 German tertiary referral centres. ${ }^{1}$ This trial found no evidence for the superiority of betahistine in low and high doses over placebo in reducing the number of acute vertigo attacks. The efficacy of loop diuretics in treating Ménière's disease is investigated by Fiorino and colleagues in this issue of The Journal of Laryngology \& Otology. They found that intravenous frusemide did not modify endolymphatic hydrops, as assessed by magnetic resonance imaging. ${ }^{2}$ Thus, these particular medical treatments of Ménière's disease have little in the way of hard evidence behind them. In contrast, the evidence for intratympanic treatment with both gentamicin $^{3}$ and methylprednisolone, ${ }^{4}$ although invasive, seems to offer better hope of symptom control.

The positive effect of tobacco smoking cessation for patients with head and neck cancer is well known, with treatment modality influencing smoking behaviour in patients with laryngeal cancer. ${ }^{5}$ How to best achieve smoking cessation is contentious. An article in this issue of The Journal looks at the success of financial incentives in stopping smoking. ${ }^{6}$ Ghosh and colleagues found that patients with head and neck cancer enrolled to receive financial incentives to stop smoking were no more likely to give up tobacco than those not incentivised in this way. This is in line with similar studies, with only 1 of 19 trials included in a recent Cochrane review showing higher quit rates when incentives were used. ${ }^{7}$

Finally, a number of recent articles have focused on the management of epistaxis in patients who are anticoagulated; the findings demonstrate considerable variability and uncertainty in the treatment of these patients. ${ }^{8,9}$ Many practitioners recommend the cessation of anticoagulants in patients admitted to hospital with epistaxis. In this issue, Bola and colleagues conclude that patients anticoagulated with warfarin may be safely managed without stopping their anticoagulation, provided their international normalised ratio is at therapeutic or sub-therapeutic levels. ${ }^{10}$

\section{ROBIN YOUNGS EDWARD FISHER MUSHEER HUSSAIN JONATHAN FISHMAN Senior Editors}

\section{References}

1 Adrion C, Fischer CS, Wagner J, Gürkov R, Mansmann U, Strupp M. Efficacy and safety of betahistine treatment in patients with Meniere's disease: primary results of a long term, multicentre, double blind, randomised, placebo controlled, dose defining trial (BEMED trial). BMJ 2016;352:h6816

2 Fiorino F, Mattellini B, Vento M, Mazzocchin L, Bianconi L, Pizzini FB. Does the intravenous administration of frusemide reduce endolymphatic hydrops? J Laryngol Otol 2016;130: $242-7$

3 Watson GJ, Nelson C, Irving RM. Is low-dose intratympanic gentamicin an effective treatment for Ménière's disease: the Birmingham experience. J Laryngol Otol 2015;129:970-3

4 She W, Lv L, Du X, Li H, Dai Y, Lu L et al. Long-term effects of intratympanic methylprednisolone perfusion treatment on intractable Ménière's disease. J Laryngol Otol 2015;129:232-7

5 Narwani V, Harries M. Treatment modality: a predictor of continued tobacco use after treatment in patients with laryngeal cancer. J Laryngol Otol 2014;128:153-8

6 Ghosh A, Philiponis G, Bewley A, Ransom ER, Mirza N. You can't pay me to quit: the failure of financial incentives for smoking cessation in head and neck cancer patients. J Laryngol Otol 2016;130:278-83

7 Cahill K, Perera R. Competitions and incentives for smoking cessation. Cochrane Database Syst Rev 2011;(4):CD004307

8 Hall AC, Blanchford H, Chatrath P, Hopkins C. A multi-centre audit of epistaxis management in England: is there a case for a national review of practice? J Laryngol Otol 2015;129:454-7

9 Fox R, Nash R, Liu Z-W, Singh A. Epistaxis management: current understanding amongst junior doctors. $J$ Laryngol Otol 2016;130:252-5

10 Bola S, Marsh R, Braggins S, Potter C, Hickey S. Does the continuation of warfarin change management outcomes in epistaxis patients? J Laryngol Otol 2016;130:256-60 